\title{
Effects of Cigarette Smoke on Salivary Protein Tyrosine NitRATION
}

\author{
D. Weiner ${ }^{1}$, E. V. Khankin ${ }^{2}$, Y. Levy ${ }^{3}$, D. Aizenbud ${ }^{4}$, A. Z. Reznick ${ }^{1}$ \\ ${ }^{1}$ Department of Anatomy and Cell Biology, the Bruce Rappaport Faculty of Medicine, Technion, Haifa, Israel; \\ ${ }^{2}$ Division of Molecular and Vascular Medicine, Beth Israel Deaconess Medical Center, Harvard; Medical School, Boston, MA, USA; \\ ${ }^{3}$ Internal Department D, Rambam Health Care Campus and Faculty of Medicine, Technion, Haifa, Israel; \\ ${ }^{4}$ Orthodonic and Craniofacial Center, Rambam Health Care Campus and Faculty of Medicine, Technion, Haifa, Israel
}

\begin{abstract}
Introduction: Nitration of tyrosine and tyrosine-containing proteins and their roles in pathophysiology have just recently been reviewed. Despite low yields of tyrosine modifications, nitration of tyrosine residues may inactivate important proteins. Nitrotyrosine can be formed by various nitrating agents, including peroxynitrite. Thus, the occurrence of nitrotyrosine-containing proteins in vivo should be regarded as a general indication of tissue damage induced by reactive nitrogen species such as peroxynitrite. This strongly suggests that peroxynitrite could be formed in vivo under
\end{abstract} certain pathophysiological conditions.

Objective: Our aim in this study was to elucidate the effect of cigarette smoke (CS) on nitrotyrosine formation in saliva proteins.

Methods: We exposed saliva to CS, in vitro, and used Western Blotting (WB) and monoclonal anti-nitrotyrosine antibody to assess the level of saliva protein nitration.

Results: As saliva contains extensive amounts of nitrites, it was no surprise that at basal levels, saliva proteins, albumin, and $\alpha$-amylase all were already nitrated. The WB also revealed that with continuous exposure to CS the tyrosine nitration of both albumin and $\alpha$ amylase is declining significantly after $3 \mathrm{~h}$. A quite similar effect was seen after exposure to aldehydes, but to a less extent as compared to CS. Exposure of nitrotyrosine-modified bovine serum albumin (BSA-N) to aldehydes, produced a similar effect, meaning a decrease in tyrosine nitration.

Conclusions: These findings might be explained by the possible ability of CS aldehydes to reduce proteinbound nitro group to an amine. Another proposed mechanism is that CS unsaturated aldehydes react with proteins mainly through Michael addition reaction; leading to the generation of stable aldehyde-protein adducts (APA). Thus, it may react with nitro groups of saliva proteins, like albumin or $\alpha$-amylase, to generate APA, which ultimately, may not be recognized by our antibody. Another possible mechanism, is interaction between the aldehyde group with the hydroxyl group of the 3-nitrotyrosine, forming a hemiacetal, which is not recognized by the antibody. This mechanism might explain the difference in the 'denitration' effects caused by the saturated aldehyde acetaldehyde, which exists in large amounts in CS, and unsaturated aldehydes. Therefore, it is possible that the main player in the CS smoke "denitration" effect on salivary proteins is the aldehyde group and not the double bond of unsaturated aldehydes.

Key words: Tyrosine nitration, cigarette smoke, aldehydes, amylase

\section{INTRODUCTION}

Nowadays, about one third of adults in the USA are known to be smokers and smoking rates are increasing, especially among the female population $[1,2]$. Cigarette smoke (CS) is presently known as the main cause of cancer, chronic bronchitis, emphysema, cardiovascular disease, and a leading cause of death worldwide [3]. Cigarette smoke is also a multipotent carcinogenic mixture that can cause cancer in numerous different organs, and a strong independent risk factor for cancers of oral cavity, upper respiratory tract, lung cancer and upper gastrointestinal tract [3-5]. CS contains over 4800 different chemicals, 400 of which are proven carcinogens. These carcinogens include aromatic amines, nitrosamines, oxidants such as oxygen free radicals and also high concentrations of toxic volatile aldehydes. All are, presumably, major causes of damage to various biomolecules exposed to CS [6].

It is well established that CS alters saliva components leading to a decrease in the ability of saliva to act as a protective fluid against oxidative damage, carcinogens, bacterial overgrowth and more. The mechanisms by which CS alters saliva components and activity is not fully understood. In the human oral cavity, nitrate secreted as a salivary component is reduced to nitrite and nitric oxide (NO) by certain bacteria, and salivary nitrite may be transformed to $\mathrm{NO}, \mathrm{NO}_{2}$, and $\mathrm{N}_{2} \mathrm{O}_{3}$ which can lead to tyrosine nitration. It is well known that $\mathrm{NO}$ is an antimicrobial compound as well as a physiologically important compound. The concentration of nitrate in saliva $(0.2-2.5 \mathrm{mM})$ is depen- 
dent on the amount of nitrate ingested. The concentration of nitrite in saliva $(0.05-1.0 \mathrm{mM})$ is dependent on the concentration of nitrate. The nitrite and NO formed in the human oral cavity can be oxidized by molecular oxygen and by salivary peroxidase producing $\mathrm{NO}_{2}^{-}[7]$.

The concomitant production of $\mathrm{NO}$ and superoxide constitutes the main source of tyrosine nitration. Known sites of tyrosine nitration appear to be in close proximity to acidic residues, most containing turn inducing residues, but not cysteine or methionine residues. In most reported studies, nitration of tyrosine has been associated with a significant loss of function of the nitrated protein. Protein nitration has been utilized as a biological marker to monitor disease onset, progression, and outcome. A number of studies have also indicated that nitration of proteins at least in vitro and in cell model systems could significantly alter protein function, alter protein turnover, influence immune responses, and possibly be involved in signal transduction processes.

In addition to the potential of protein nitration to hinder protein function, recent data raise the issue of whether protein nitration might also be a cellular signaling mechanism. To be considered a cellular signaling mechanism, protein nitration must meet four basic criteria: controlled rates of formation, specificity, modification of target protein and cell function, and reversibility. The specificity of protein nitration and modification of protein and cell functions by protein nitration have been demonstrated. However, very little evidence exists regarding the reversibility by a protein "denitration" process in vivo. Recently Koeck et al [8] discovered that isolated rat liver mitochondria are capable of nitrotyrosine clearance during a 20-min episode of hypoxia-anoxia and that nitrotyrosine immunoreactivity reappears during reoxygenation in an L-arginine-dependent way at protein spots that matched the spots before hypoxia- anoxia [8]. However, there is no mentioning in the literature of 'nitratase' or denitrating enzymes in human saliva or plasma.

Many of the abnormalities associated with CS, including endothelial dysfunction, proinflammatory effects on vessel wall, prothrombotic effects such as increased platelet reactivity, reduced endogenous fibrinolysis and lipid peroxidation can largely be explained by the effect of increased oxidative and nitrosative stress [7]. Our working hypothesis was that when CS contacts saliva, there is a massive increase in reactive oxygen species (ROS), reactive nitrogen species (RNS), and aldehydes which, in turn, cause protein alterations in the form of tyrosine nitration. As a result, there is a decline in the defense mechanism of the saliva especially in its antioxidative properties. Thus, external addition of antioxidants can neutralize the effect of CSoriginated oxidants and could act as an effective means in neutralizing the toxic effect of smoking.

\section{Material And Methods}

The study was performed in accord with the Declaration of Helsinki for Human Research and the study protocol was approved by an institutional Ethics Committee.
Whole saliva, which is basically total oral fluid, was collected from healthy male and female nonsmokers under non-stimulatory conditions in the morning. For the collection, which was performed at least $1 \mathrm{~h}$ after eating; volunteers were asked to generate saliva in their mouths and to spit it into a wide test tube for 10-15 min. Following collection, saliva was immediately centrifuged $(1000 \mathrm{x} g, 3 \mathrm{~min})$ to remove squamous cells and cell debris. The fresh supernatant was immediately used for CS and aldehydes studies, and tyrosine nitration studies were performed.

The cigarettes used in this study were popular commercial cigarettes ('Time' cigarettes; Dubek Ltd., Tel Aviv, Israel) containing $14 \mathrm{mg}$ of tar and $0.9 \mathrm{mg}$ of nicotine per cigarette. Acrolein and crotonaldehyde were purchased from Sigma-Aldrich (St. Louis, MO), acetaldehyde from Fisher Scientific

\section{Exposure of Saliva to Cigarette Smoke (CS)}

An in vitro study was carried out using 'Time' cigarettes combined with a vacuum system, as described previously [6, 9]. Saliva $(4-5 \mathrm{ml})$ was placed in $250 \mathrm{ml}$ flasks with a sidearm to which the cigarettes were attached. A reproducible vacuum was created in the flask, and after opening the vacuum to the lighted cigarette for $5 \mathrm{~s}, 80$ to $100 \mathrm{ml}$ of CS 'puffs' were drawn into the flask. Flasks were incubated in a metabolic shaker for a total of $3 \mathrm{~h}$ at $37^{\circ} \mathrm{C}$. In a given experiment, puffs were administered to the flask over a 3 -h time period at 20-min intervals, for a total of nine times. Samples for biochemical analysis were removed from the flasks at zero time and then at 1, 2, and $3 \mathrm{~h}$.

\section{Exposure of Saliva to Purified Aldehydes}

4-5 $\mathrm{ml}$ of human saliva was treated with an aldehyde mixture of crotonaldehyde and acrolein (unsaturated aldehydes) similar to that reported to be present in a mainstream smoke of a single 2R1 University of Kentucky reference cigarette (5), to give a final concentration of $0.8 \mu \mathrm{mol} / 4 \mathrm{ml}$ acrolein and $0.21 \mu \mathrm{mol} / 4 \mathrm{ml}$ crotonaldehyde (AL). Another $4-5 \mathrm{ml}$ of saliva was treated with acetaldehyde (saturated aldehydes) (ACET-AL) to give a final concentration of 20 $\mu \mathrm{mol} / 4 \mathrm{ml}$. Aldehydes were administered to the flask over a 3 -h time period at 20-min intervals, for a total of nine times. Samples for biochemical analysis were removed from the flasks at zero time and at 1,2, and 3 h. Flasks were incubated in a metabolic shaker for a total of $3 \mathrm{~h}$ at $37^{\circ} \mathrm{C}$.

For positive control, we exposed bovine serum albumin (BSA) (Sigma-Aldrich, St. Louis, MO) and nitrotyrosine-modified BSA (BSA-N) (Alexis Corporation, Lausen, Switzerland) at parallel amounts to those of saliva albumin to volatile aldehydes in the same manner.

\section{Addition of Glutathione (GSH) to Saliva}

GSH was added to saliva at zero time and flasks were incubated in a metabolic shaker for a total of $30 \mathrm{~min}$ at $37^{\circ} \mathrm{C}$, prior to the first smoking puff or aldehyde addition, at concentrations of $1 \mathrm{mM}$ (GSH from Sig- 
ma-Aldrich, St. Louis, MO). In addition, in all experiments, a control without the compounds was run with no difference in the assay conditions.

\section{Nitrite Concentrations Measurement - Griess REAGENT ASSAY}

As a measure of the intensity of CS puffs, the nitrite levels in saliva were assessed using the commercially available Griess reagent [10] (Sigma-Aldrich, St. Louis, MO), according to the manufacturer's instructions. The products of the reaction between nitrites and Griess reagent were measured spectrophotometrically at $540 \mathrm{~nm}$ and calibrated against the calibration curve constructed with the use of $\mathrm{NaNO}_{2}$.

\section{Protein Immunoblotting (Western Blot)}

Following the various treatments, the saliva samples were spinned down for $1.5 \mathrm{~min}$, boiled for $10 \mathrm{~min}$ at $95^{\circ} \mathrm{C}$ in sample buffer and separated on $10 \%$ Acrylamide SDS-PAGE. Monoclonal antibody to nitrotyrosine for nitration detection (Chemicon International, Billerica, MA, USA), Secondary antibody was goat anti-mouse IgG (Santa Cruz Biotechnology, Santa Cruz, CA, USA) according to manufacturer's instructions. Densitometric quantitative analysis of the protein bands detected by Western blot, were carried out using "Tina" software (ISBE University of Manchester, UK).

\section{StATISTICAL ANALYSis}

Statistical analysis was performed using an unpaired ttest. To determine statistical significance, the ranges, means, and SD were computed. Results are reported as means \pm SD. Statistical significance was set at $\mathrm{P}<0.05$.

\section{RESULTS}

The Effect of CS and Volatile Aldehydes on Salivary Protein Tyrosine Nitration

We checked whether exposure of human saliva to CS and aldehydes is associated with more nitration of tyrosine residues of saliva proteins. We exposed the saliva proteins to immunoblotting by PAGE using antinitrotyrosine antibody (in all the results $\mathrm{n}=3$ ).

As shown in Fig. 1A, saliva proteins (albumin and $\alpha$-amylase) were both already nitrated at time 0 and exposure to CS for $3 \mathrm{~h}$ caused a decrease in tyrosine nitration of both albumin and $\alpha$-amylase $(65 \pm 6.3 \%$ and $80 \pm 7.8 \%$, respectively, $\mathrm{P}<0.001$ in comparison to time 0 ). As we received these results we examined if there is a change in protein concentration by the BioRad protein assay. There was no reduction in protein during exposure to CS for $3 \mathrm{~h}$ (data not shown). Fig. $1 \mathrm{~B}$ shows that exposure to air did not induce any change in saliva protein tyrosine nitration during $3 \mathrm{~h}$.

As a mean to understand our results we decided to expose BSA to CS. BSA did not show any tyrosine nitration at time zero and after $3 \mathrm{~h}$ (data not shown). As BSA-N comes in very small amounts, it was impossible to expose it to CS. It is also important to mention
A

B

Albumin

$\alpha$-Amylase

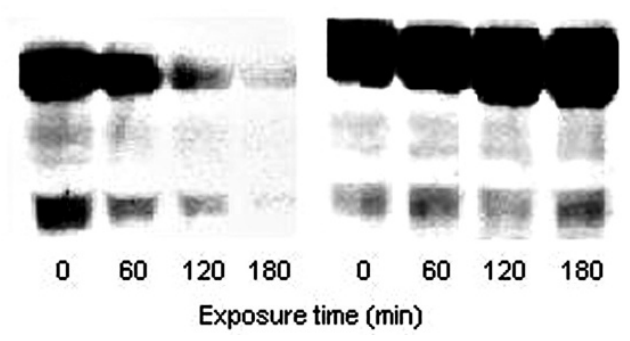

Fig. 1. Immunoblotting of antinitrotyrosine Ab using PAGE analysis of salivary proteins at zero time and after 3-h exposure to cigarette smoke - CS (A) and air (B).

that we examined saliva albumin and not serum albumin; therefore they probably behave in a different manner. Exposure of purified human saliva $\alpha$-amylase to CS did not produce any change in tyrosine nitration, and it was not nitrated from the beginning like $\alpha$-amylase in our saliva (data not shown). We continued with our research and determined the possible damage of CS to saliva proteins and enzymes by adding aldehydes and examined their effect on tyrosine nitration.

\section{EFFECTS OF UNSATURATED AND SATURATED Aldehydes on Salivary Protein Tyrosine Nitration}

As shown in Fig. 2A, unsaturated aldehydes, acrolein and crotonaldehyde, induced a similar to CS effects and reduced tyrosine nitration of albumin and $\alpha$-amylase after $3 \mathrm{~h}(20 \pm 1.8 \%$ and $40 \pm 3.4 \%$, respectively), but to a much less extent in comparison to CS $(\mathrm{P}<0.001)$. The saturated aldehyde, acetaldehyde, had the most powerful effect in reducing tyrosine nitration of albumin after $3 \mathrm{~h}$ in comparison to both CS and unsaturated aldehyde $(96 \pm 12 \%$ vs. $80 \pm 7.8 \%$ vs. 40 $\pm 3.4 \%$ respectively; $\mathrm{P}<0.001$ compared to time 0$)$ and caused complete "denitration" of $\alpha$-amylase (Fig. $2 \mathrm{~B}$ ).

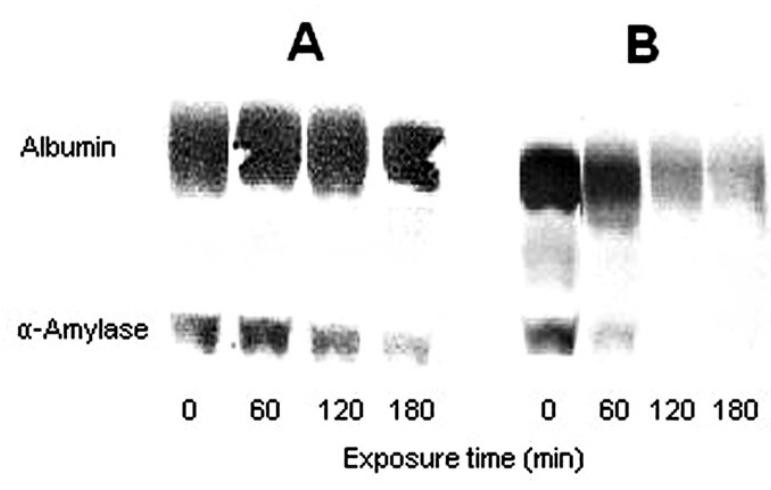

Fig. 2. Immunoblotting of antinitrotyrosine Ab using PAGE analysis of salivary proteins at zero time and after 3-h exposure to unsaturated (A) and saturated aldehydes (B).

To verify our results we exposed BSA and nitrated BSA (BSA-N) to unsaturated aldehydes and acetalde- 


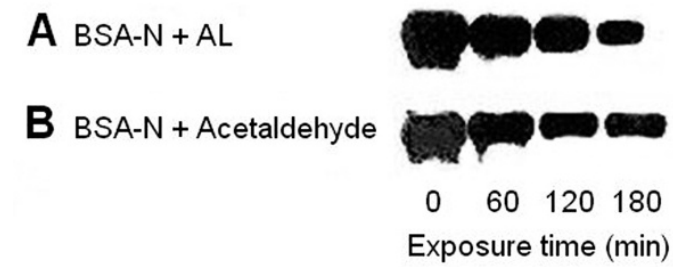

Fig. 3. Immunoblotting of antinitrotyrosine Ab using PAGE analysis of BSA-N at zero time and after 3-h exposure to unsaturated (A) and saturated aldehydes (B).

hyde. BSA produced no tyrosine nitration at all times (data not shown). On the other hand, exposure of BSA-N to aldehydes produced a similar effect to that of human saliva albumin, meaning, there was "denitration" of tyrosine after $3 \mathrm{~h}$ (Fig. 3A and B). Exposure of purified human saliva $\alpha$-amylase to aldehydes did not produce any change in tyrosine nitration, and it was not nitrated from the beginning like $\alpha$-amylase in our saliva (data not shown).

\section{Effects of GSH on Tyrosine Nitration of SALIVA Proteins}

To elucidate whether GSH had an effect on this phenomenon, and as described before, we incubated the saliva with GSH prior to exposure to CS and aldehydes. We found that there was some protective effect of GSH against the decrease in tyrosine nitration.

\section{Effects of CS on Salivary Protein Tyrosine Nitration in the Presence of GSH}

Fig. 4 shows the effect of $1 \mathrm{mM}$ GSH addition to saliva and exposure to CS. It is noticed that GSH had a significant effect against CS denitration of albumin $(20 \pm 4.2 \%$ vs. $65 \pm 6.3 \%, \mathrm{P}<0.001)$ and $\alpha$-amylase denitration (46 $\pm 3.8 \%$ vs. $80 \pm 7.8 \%, \mathrm{P}<0.05)$.

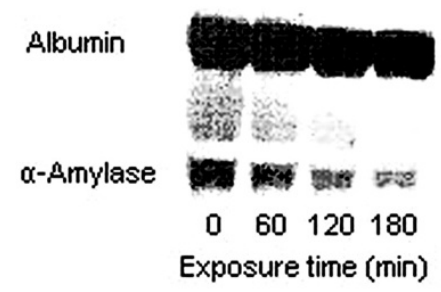

Fig. 4. Immunoblotting of antinitrotyrosine Ab using PAGE analysis of salivary proteins at zero time and after 3 -h exposure to $\mathrm{CS}+\mathrm{GSH}$.

\section{EFFECTS OF UnSATURATED AND SATURATED Aldehydes on Salivary Protein Tyrosine Nitration in the Presence of GSH}

Fig. 5A shows the effect of $1 \mathrm{mM}$ GSH addition to saliva and exposure to unsaturated aldehydes. GSH had a significant effect against unsaturated aldehydes denitration of both saliva albumin $(3 \pm 0.7 \%$ vs. $20 \pm 1.8 \%, \mathrm{P}<0.001)$ and $\alpha$-amylase $(10 \pm 1.7 \%$ vs. $40 \pm 3.4 \%, \mathrm{P}<0.001)$. Fig. $5 \mathrm{~B}$ shows the effect of $1 \mathrm{mM}$ GSH addition to saliva and exposure to saturated aldehyde, acetaldehyde. GSH had a significant effect against acetaldehyde denitration of both saliva albumin $(19 \pm 3.1 \%$ vs. $48 \pm 5.9 \%, \mathrm{P}<0.001)$ and $\alpha$-amylase (52 $\pm 4.9 \%$ vs. $96 \pm 12 \%, \mathrm{P}<0.001)$.

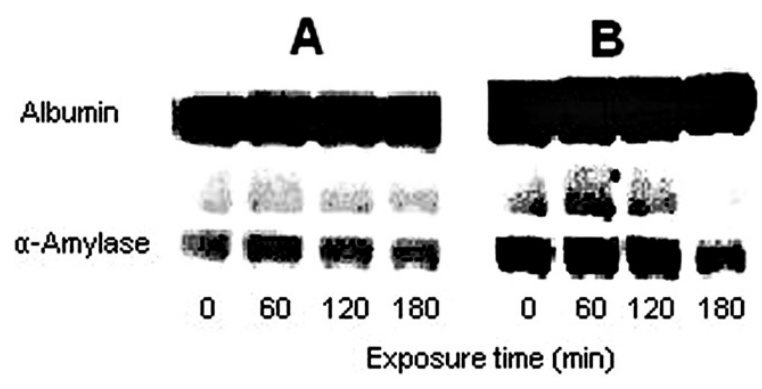

Fig. 5. Immunoblotting of antinitrotyrosine Ab using PAGE analysis of salivary proteins at zero time and after $3-\mathrm{h}$ exposure to unsaturated aldehydes + GSH (A) and saturated aldehyde (B).

\section{Discussion}

Cigarette smoke is associated with a variety of human pathologies including atherosclerosis, CVD and cancer [11]. Ma et al [12] recently demonstrated that oxidative and nitrative stress contributes to the development of oral carcinogenesis through DNA damage. RNS in the form $\mathrm{NO}_{3}$ and $\mathrm{NO}_{2}$ and aldehydes, play a key role in human cancer development because they can cause DNA base alterations, strand breaks, damaged tumor suppressor genes, and an enhanced expression of protooncogenes. Salivary nitrosamine production and metabolism are also based on the dietary nitrates $\left(\mathrm{NO}_{3}{ }^{-}\right)$, which are absorbed from the upper gastrointestinal tract and actively concentrated from the plasma into the saliva by the salivary glands through an active transport system similar to that for iodide and thiocyanate [13].

In the oral cavity the salivary nitrates are turned into nitrites $\left(\mathrm{NO}_{2}^{-}\right)$, which are of special importance as carcinogenesis promoters because they react with amines and amides to form the carcinogenic nitrosamines [14, 15]. Salivary composition of OSCC patients is substantially altered with respect to free radical-involved mechanisms. All salivary RNS analyzed in these patients were significantly higher and all salivary antioxidants significantly reduced. Whether the demonstrated increase in RNS (3-fold in nitrites, which are the precursors of carcinogenic nitrosamines) was the event that led to the consumption and reduction of the salivary antioxidant systems remains an open question [7].

Several human studies have investigated the effects of smoking on salivary damage. However, the exact mechanism by which CS components cause this damage is not fully understood. Therefore, we have decided to study the effects of CS components, especially volatile aldehydes, on salivary damage through nitration of enzymes and proteins. Nitration of tyrosine 
and tyrosine-containing proteins and their roles in pathophysiology have recently been reviewed by Ischiropoulos [16]. Despite low yields of tyrosine modifications, nitration of tyrosine residues inactivates important proteins [17-22].

Nitration of tyrosine residues by peroxynitrite disrupts the phosphorylation of tyrosine residues in proteins involved in cell signaling networks [23]. However, more than a decade ago, an enzymatic activity, which modifies nitrotyrosine containing proteins (a 'nitrotyrosine denitrase'), has been reported in homogenates of rat tissue. The activity is increased about twofold in spleen extracts after endotoxin (bacterial lipopolysaccharide) treatment of animals, suggesting that the activity is inducible or regulated [24]. Thus, nitration of tyrosine could be one of the important post-translational modifications of proteins, the levels of which should be regulated biologically. It should be noted that nitrotyrosine can be formed by various nitrating agents, including peroxynitrite, nitrous acid, $\mathrm{N}_{2} \mathrm{O}_{3}$ and $\mathrm{NO}_{2}[25,26]$. NO may also react directly with tyrosyl radicals (e.g., stable radicals such as that found in ribonucleotide reductase or those formed by $\mathrm{H}_{2} \mathrm{O}_{2}$ or others oxidants) to form nitroso or nitro derivatives. Thus, the occurrence of nitrotyrosine-containing proteins in vivo should be regarded as a general indication of tissue damage induced by reactive nitrogen species such as peroxynitrite. As one of our aims was to elucidate the effect of CS on nitrotyrosine formation, we used WB and exposed our saliva proteins to monoclonal anti-nitrotyrosine antibody. As saliva contains extensive amounts of nitrites, it was no surprise that at basal levels, saliva proteins, albumin and $\alpha$-amylase, were already nitrated.

The WB also revealed that with exposure to CS the tyrosine nitration of both albumin and $\alpha$-amylase is declining significantly after $3 \mathrm{~h}(65 \%$ and $80 \%$, respectively in comparison to time 0 (Fig. 1). A quite similar effect was seen after exposure to unsaturated aldehydes, but to a less extent as compared to CS (Fig. 2A). A phenomenon that kept repeating itself was the significant effect of acetaldehyde on the "denitration" of albumin and especially $\alpha$-amylase- $48 \%$ for albumin and $96 \%$ for $\alpha$-amylase (Fig. 2B). At this stage we decided to verify whether our results are real "denitration" from tyrosine residues or non specific findings. We exposed nitrotyrosine-modified BSA (BSA-N) to unsaturated aldehydes and acetaldehyde, and received a similar effect, meaning a decrease in tyrosine nitration (Fig. 3A and B). For technical reasons it was not possible to expose BSA-N to CS. Exposure of pure BSA and pure $\alpha$-amylase to CS and volatile aldehydes produced no tyrosine nitration at all times (data not shown).

These findings might be explained by the possible ability of aldehydes to reduce protein-bound nitro group to an amine [27]. Thus, if aldehydes can reduce nitro group of proteins to an amine, it would result in the vanishing of nitrotyrosine modified proteins. Another proposed mechanism is that aldehydes react with proteins mainly through Michael addition reaction; leading to the generation of stable aldehyde-protein adducts (APA). Thus, it may react with nitro-groups of saliva proteins, like albumin or $\alpha$-amylase, to generate
APA, which, ultimately, may not be recognized by our antibody [28]. Another possible mechanism, is interaction between the aldehyde group with the hydroxyl group of the 3-nitrotyrosine, forming a hemiacetal, which is not recognized by the antibody (Fig. 6). This mechanism might explain the difference in "denitration" between saturated aldehyde, acetaldehyde, which exists in large amounts in CS, and unsaturated aldehydes. It is possible that the main player in "denitration" of salivary proteins is the aldehyde group and not the double bond of unsaturated aldehydes.
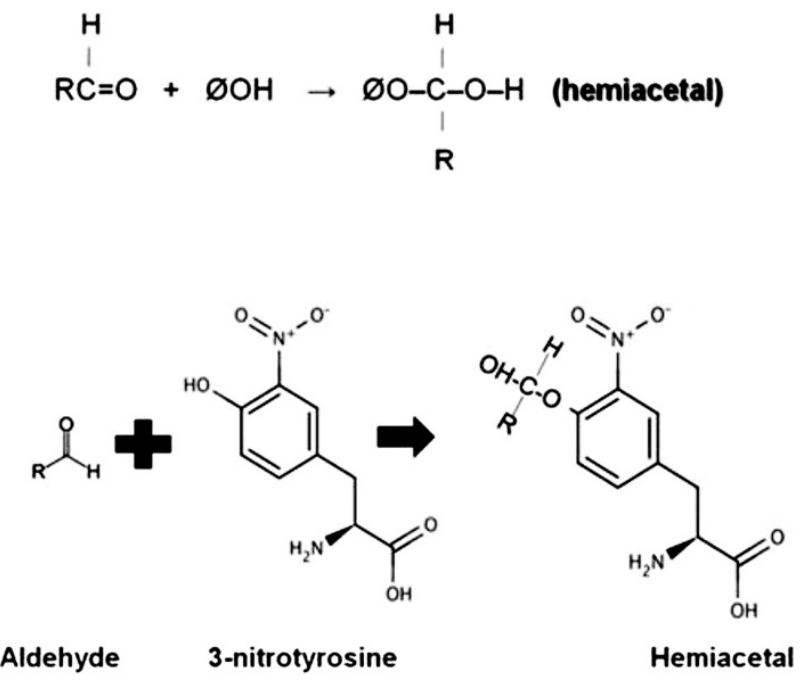

Fig. 6. Possible mechanism for aldehyde-induced 'denitration'.

These results were confirmed when we added GSH to saliva prior to exposure to CS and aldehydes and received a significant effect of protection against "denitration" of tyrosine. The effect was more intense for tyrosine nitration of albumin than $\alpha$-amylase, but for all experiments there was more than $50 \%$ protection (Fig. 4-5). GSH is also able to interact with the aldehyde groups of different aldehydes.

Reviewing the literature, this is the first time we saw that there is tyrosine nitration at basal levels. This could be explained by the large presence of nitrates and nitrites in human saliva. They are increased due to the presence of microbial flora in the oral cavity and have a role as antimicrobial chemicals. Even though our aim was to show an increase in tyrosine nitration after exposure to CS, we received a quite interesting result, suggesting protein alterations which lead, in the case of $\alpha$-amylase, to reduced activity.

Our results together with previous studies we have conducted $[29,30]$ suggest an explanation for the involvement of aldehydes and RNS in damage to salivary components and a possible mechanism of CS induced damage to saliva, which may lead to the progression of oral cavity associated diseases. Future in vitro studies should include using saliva from smokers and comparing to non-smokers and in vivo studies of both smokers and non-smokers and treatment with antioxidants supplements, such as GSH and epigallocatechine-3-gallate (EGCG) that directly reacts with 
tyrosyl radicals, thus preventing their transformation into nitrotyrosine.

Acknowledgement: This work was supported by the Rappaport Research Institute at the Faculty of Medicine of the Technion Israel and the Krol Foundation of Barnegat NJ, USA.

Conflicts of interest: The authors declare no conflicts of interest in relation to this article.

\section{REFERENCES}

1. Kuper H, Adami HO, Boffetta P. Tobacco use, cancer causation and public health impact. J Intern Med 2002; 251: 455-66.

2. Ozlu T, Bulbul Y. Smoking and lung cancer. Tuberk Toraks 2005; 53: 200-9.

3. Salaspuro VJ, Hietala JM, Marvola ML, Salaspuro MP. Eliminating carcinogenic acetaldehyde by cysteine from saliva during smoking. Cancer Epidemiol Biomarkers Prev 2006; 15: 146-9.

4. Anonymous. Tobacco smoking and involuntary smoking. IARC monographs on the evaluation of carcinogenic risk of chemicals to humans. 83. Lyon (France): IARC; 2004.

5. Sasco AJ, Secretan MB, Straif K. Tobacco smoking and cancer: a brief review of recent epidemiological evidence. Lung Cancer 2004; 45 Suppl: 53-9.

6. Nagler R, Lischinsky S, Diamond E, Drigues N, Klein I, Reznick AZ. Effect of cigarette smoke on salivary proteins and enzyme activities. Arch Biochem Biophys 2000; 379: 229-36.

7. Takahama U, Hirota S, Takayuki O. Detection of nitric oxide and its derivatives in human mixed saliva and acidified saliva. Methods in Enzymol 2008; 440: 381-96.

8. Koeck T, Fu X, Hazen SL, Crabb JB, Stuehr DJ, Aulak KS. Rapid and selective oxygen regulated protein tyrosine denitration and nitration in mitochondria. J Biol Chem 2004; 279: 27257-62.

9. Hasnis E. PHD thesis, 2004, Technion, Israel

10. Huygen IC. Reaction of nitrogen dioxide with Griess type reagents. Anal Chem 1970; 42: 407-9.

11. Mallampalli A, Guntupalli KK. Smoking and systemic disease. Med Clin North AM 2004; 88: 1431-51.

12. Ma N, Tagawa T, Hiraku Y, Murata M, Ding X, Kawanishi S. 8-Nitroguanine formation in oral leukoplakia, a premalignant lesion. Nitric Oxide 2006; 14:137-43.

13. Tenovou J. The biochemistry of nitrates, nitrites, nitrosamines and other potential carcinogens in human saliva. J Oral Pathol 1986; 15:303-7.

14. Xia DS, Deng DJ, Wang SL. Destruction of parotid glands affects nitrate and nitrite metabolism. J Dent Res 2003; 82:101-5.

15. Deng DJ. Progress of gastric cancer etiology: N-nitrosamides. World J Gastroenterol 2000; 6: 613-18.

16. Ischiropoulos H. Biological tyrosine nitration: a pathophysiological function of nitric oxide and reactive oxygen species. Arch Biochem Biophys 1998; 356: 1-11.

17. MacMillan-Crow LA. Peroxynitrite-mediated inactivation of manganese superoxide dismutase involves nitration and oxidation of critical tyrosine residues. Biochemistry 1998; 37: 1613-22
18. Yamakura F, Taka H, Fujimura T, Murayama K. Inactivation of human manganese-superoxide dismutase by peroxynitrite is caused by exclusive nitration of tyrosine 34 to 3-nitrotyrosine. J Biol Chem1998; 273: 14085-89.

19. MacMillan-Crow LA, Crow JP, Kerby JD, Beckman JS, Thompson JA. Nitration and inactivation of manganese superoxide dismutase in chronic rejection of human renal allografts. Proc Natl Acad Sci USA 1996; 93: 11853-58.

20. Berlett BS, Levine RL, Stadtman ER. Carbon dioxide stimulates peroxynitrite-mediated nitration of tyrosine residues and inhibits oxidation of methionine residues of glutamine synthetase: both modifications mimic effects of adenylylation. Proc Natl Acad Sci USA 1998; 95: 2784-9.

21. Ara J, Przedborski S, Naini AB, Jackson-Lewis V, Trifiletti RR, Horwitz J, Ischiropoulos H. Inactivation of tyrosine hydroxylase by nitration following exposure to per oxynitrite and 1-methyl-4-phenyl-1,2,3,6-tetrahydropyridine (MPTP). Proc Natl Acad Sci USA 1998; 95: 7659-63.

22. Roberts ES, Lin H, Crowley JR, Vuletich JL, Osawa Y, Hollenberg PF. Peroxynitrite-mediated nitration of tyrosine and inactivation of the catalytic activity of $\mathrm{cy}$ tochrome P450 2B1. Chem Res Toxicol 1998; 11: $1067-$ 74.

23. Kong SK, Yim MB, Stadtman ER, Chock PB. Peroxynitrite disables the tyrosine phosphorylation regulatory mechanism: lymphocyte-specific tyrosine kinase fails to phosphorylate nitrated cdc2(6-20) $\mathrm{NH}_{2}$ peptide. Proc Natl Acad Sci USA 1996; 93: 3377-82.

24. Kamisaki Y, Wada K, Bian K, Balabanli B, Davis K, Martin E, Behbod F, Lee Y-C, Murad F. An activity in rat tissues that modifies nitrotyrosine-containing proteins. Proc Natl Acad Sci USA 1998; 95: 11584-89.

25. Halliwell B. What nitrates tyrosine? Is nitrotyrosine specific as a biomarker of peroxynitrite formation in vivo? FEBS Lett 1997; 411: 157-60.

26. Ohshima H, Friesen M, Brouet I, Bartsch H. Nitrotyrosine as a new marker for endogenous Nitrosation and nitration of proteins. Food Chem Toxicol 1990; 28: 647-52.

27. Bolan EA, Gracy KN, Chan J, Trifiletti RR, Pickel VM. Utrastructural localization of nitrotyrosine within the caudate-putamen nucleus and the globus pallidus of normal rat brain. J Neurosci 2000; 20: 4798-808.

28. Uchida K, Kanematsu M, Sakai K, Matsuda T, Hattori N, Mizuno Y, Suzuki D, Miyata, Noriko Noguchi T, Niki E, Osawa T. Protein-bound acrolein: Potential markers for oxidative stress. Proc Natl Acad Sci USA 1998; 95: 488287.

29. Weiner D, Levy Y, Khankin EV, Reznick AZ. Inhibition of salivary amylase activity by cigarette smoke aldehydes. J Physiol Pharmacol 2008; 59 Suppl 6: 727-37.

30. Weiner D, Khankin EV, Levy Y, Reznick AZ. Effects of cigarette smoke borne reactive nitrogen species on salivary alpha-amylase activity and protein modifications. J Physiol Pharmacol 2009; 60 Suppl 5: 127-32.

Address for correspondence:

AZ Reznick

Department of Anatomy and Cell Biology

The Bruce Rappaport Faculty of Medicine, Technion

Haifa, Israel

Phone: +97248295388

E-mail: Reznick@tx.technion.ac.il 